\title{
Social Media and the Dialectic of Enlightenment
}

\author{
Henrik Juel
}

\author{
Department of Communication, Business and Information Technologies, Roskilde University, \\ Roskilde, Denmark, hjuel@ruc.dk, http://akira.ruc.dk/ hjuel/
}

\begin{abstract}
My reflections in this paper concern revitalizing the critical potential of certain core concepts of Max Horkheimer and Theodor W. Adorno's Dialectic of Enlightenment (first published 1944) and bringing it to bear on the digital era in general and in particular on the phenomenon of modern social media. I find that the central philosophical critique of Dialectic of Enlightenment runs deeper than just a critique of contemporary (and perhaps now out-dated) media technique and cultural habits. It is a critical view of the process of civilization, economy and enlightenment as such, a critical view of the seemingly self-evident notion of pure reason, science and technology. What Horkheimer and Adorno are trying to capture and reflect is the very process of rationality backlashing into irrationality. We seem to have reached the era of mathematics and exact calculation, but this leaves us with no sense of control or meaningfulness, and in the face of crisis and systemic contradictions in the now global society we tend to regress and rely on older, more primitive forms of sense-making and coping: magic, mythology and metaphysics - even ritual behaviour. But these philosophical reflections, can they help us evaluate the role of today's social media?
\end{abstract}

Keywords: Critical Theory, Dialectics, Enlightenment, Social Media, Alienation, Fetishism, Commodities

Acknowledgement: The author wishes to thank Rae Duxbury for many a useful suggestion especially concerning a more communicative use of the English language. Whatever oddities and mistakes remain is entirely the responsibility of the author.

When I first saw that Critical Theories of Social Media was to be the theme at the 4th ICTS and Society-Conference in Uppsala, May 2012, I immediately began to wonder how those two categories could possibly fit together. Critical Theory in the proper sense, as laid out in the ideals and practices of the 20th century philosophical Frankfurter School, was something I had studied and discussed eagerly in my time as a young student of philosophy in Copenhagen - but that was quite a while ago, and it seemed to me, that I had not heard much about Critical Theory during the last few decades. However, Social Media was definitely something I had heard a lot about in recent years - something that was beginning to be enthusiastically studied and discussed by my students and to some extent even by some of my colleagues in the Communication Department of Roskilde University.

So I began to wonder: What will happen if once more I invite this old love of mine, Critical Theory, to go out with me - and I then take her down town to see the new show in town called Social Media? Will she smile or will she frown?

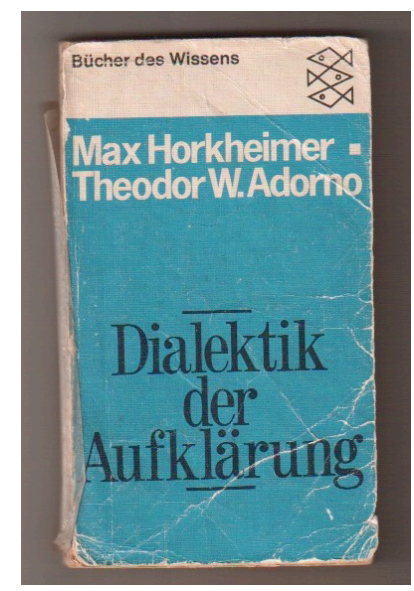

Figure 1: My old student copy (Photo HJ, 2012) 
Having conceived this rather abstract idea of applying hard core critical and perhaps even pessimistic and sarcastic philosophical analysis to the much appraised and popular social media of today - including Facebook, Twitter, dating sites and all the other consumer goods and activities, real or anticipated, that have followed the web 2.0 revolution - well, a number of images crossed my mind. I even succeeded in retaining some of these images, so that they could be part of this paper and part of my presentation at the conference. 'Retaining' is perhaps to exaggerate, but I started to look for telling images. So I searched the net looking for pictures that would offer my audience a fair idea of my internal slides how. It is amazing what you can find these days out there on the net - and how easy it is to share your ideas...

One image, however, I produced myself: a picture of my somewhat worn student copy of the book by Horkheimer and Adorno: The Dialectic of Enlightenment, in the German paperback Edition from 1969.

To me that book had always represented the programmatic peak of Critical Theory and the Frankfurter School, even though some might argue that perhaps other members of that school later on became more popular or more influential. Adorno himself would probably say that his books Negative Dialectic and Aesthetic Theory were by far the weightiest of his contributions (as, indeed, he is quoted as saying inside the cover of my 1970 Suhrkamp edition of Ästhetische Theorie).

Anyway, that small book, The Dialectic of Enlightenment, contains quite a display of critical approaches to media and culture, as well as a demonstration of what a more general method of critique of ideology could possibly mean. For me as a young student of philosophy even that strange notion of dialectic began to make some sense, once I got well into the book and the worst of the Hegelian fog lifted. Thus while it was invigorating and enlightening, I also felt the dialectic of it and I found its account of history, civilization, and rationality to be both quite captivating and disturbing. And certainly it was a very, very critical philosophy. So what would happen if I tried to let the critical theory of that book meet with the phenomenon of modern social media?

On the face of it that did not seem likely to turn out as a peaceful encounter. It is well known that The Dialectic of Enlightenment features a very pessimistic and condemning section devoted to "The Culture Industry". Horkheimer and Adorno wrote the book during the Second World War while they were refugees in America (the first version appeared in 1944), and they seem to have been rather disappointed or even shocked in meeting there the pop-culture and mass media of the day. To them the magazines, the cinema, the radio shows, the emerging TV-shows, and even the jazz music, seemed to be in the poorest of taste; stupefying in its effect; a prolongation of the production rhythm of the industry; and certainly not enlightenment. Some have objected that on the other hand they were simply displaying their elitist taste, favouring high art, the avant-garde and the obscure notion of authenticity. But as I see it, simplifying this to be a question of taste or of different modes of reception within different consumer groups would be to seriously reduce the scope of the problems they were trying to address.

In thinking about the sort of "culture industry" that Horkheimer and Adorno were castigating, an image from a TV-show of today popped up - and this could perhaps serve as an illustration of the sort of "amusement" they had in mind when writing that: "Amusement is the prolongation of work during Late Capitalism" (Horkheimer and Adorno 1969) ${ }^{1}$.

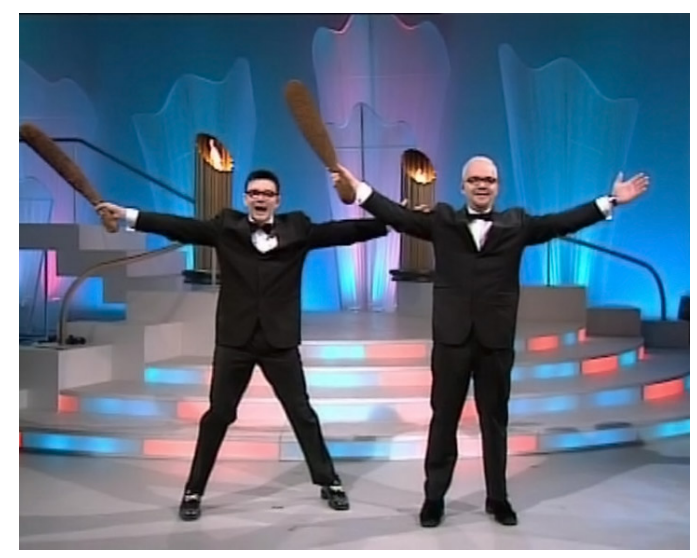

Figure 2: Entertainment - from a timely TV-show

\footnotetext{
${ }^{1}$ Translation by Henrik Juel
} 
In figure 4 we see two men on a very modern, even futuristic- looking stage that is dominated by colourful electronic light. The two men are dressed in clothes that were the fashion for men last century. They are holding clubs, as we imagine cave men did, and in the background we see some decorations looking much like classic pillars from a Greek temple but with a certain erotic twist that is due to the hot burning openings. The two celebrated TV-hosts have just descended from a broad set of stairs leading nowhere - or are the steps somehow connected directly to Heaven, allowing us this glimpse of stardom; or are the two men perhaps representing two paragons of History, role models for the mass audience of modern media?

Anyway, seen in the perspective of enlightenment this is just a nice, postmodern pass-time public service production, not meant to convey much in terms of great ideas, nor to induce democratic debate about the state of the globe. To Horkheimer and Adorno, however, this was massproduction of cultural consumer goods preaching ideology and eliminating all critical thought about the need for a change in the fundamental mechanisms of exploitation and alienation. If they were to see modern social media in that same light (as just one more technological refinement making the culture industry even more effective), then certainly they would not select the response option "like" nor label these new media with a happy 'smiley', but would click the "dislike" option and send a very sour 'smiley'.

However, I shall argue that Horkheimer and Adorno would be able to find some very positive aspects in the development of modern social media. Because what they were criticizing was the one-way mass media of their day in all its aspects and therefore not just the content of the media but also its technological development and form, they concluded that the latter aspects favoured central control and standardization.

"The step from the telephone to the radio has clearly divided the roles... No machinery for reply has been developed... "(Horkheimer and Adorno 1969, 109).

In fact Horkheimer and Adorno saw neither technique nor productivity as inherently bad; they just saw it as lamentable that the impressive technological development within the media and culture industry of their day had not been shaped so as to favour a democratic and socially liberating use. But is this not exactly what social media and web 2.0 are all about today? Have we not now, with the latest technological inventions, the possibility to reply, to connect, to produce our own content and to go in for diversification, sharing and distribution in ways that are beyond control? Would that not have pleased Horkheimer and Adorno? Would they not, after all, have come up with a happy 'smiley' here? And would they not have been surprised by this development - that these democratic, social and creative tools were not what they had then seen hidden in the cards as simply a system of domination closing in on itself?

Now one can of course argue that the liberating and creative potential of web 2.0 has not yet been realized to any large extent; it seems perhaps to be more of a romantic's dream. Research has shown that most of us are still in the role of passive consumers when on the net, with very few of us contributing to the content. Large companies are still controlling and profiting from the traffic, and you hardly ever meet the love of your life on a dating site without paying the fee to the owner of that site. And dating sites look a lot like a marketplace, where you are trying to advertise - and sell - yourself, thus joining in the exchange of consumer goods and accepting that everything be measured by the common equivalent, money. And then we are back to Horkheimer and Adorno's harsh critique of the ideological content of the culture industry. They saw all the values and ideals of the enlightenment, the bourgeois revolution, and even the dream of civilization itself as being betrayed and perverted, while being paraded by the advertising businesses and the rest of the culture industry as being fulfilled. That is the core of their critique.

"Personality hardly means anything more than splendid white teeth and being free of arm sweat and emotions"(Horkheimer and Adorno 1969, 150). ${ }^{2}$

Critique of ideology can be simply defined as "critique of promises parading as fulfilled". That at least was the formula I coined myself when I first read their book as a young student and tried to make some sense of it. I was underlining and adding little notes directly into my copy and I was rather perplexed by the way they always turned concepts inside out (that must be the "dialectic" of it, I thought) and it was very distressing, because I had to present an overview of the book in class at the university the next day. Then all of a sudden I saw I had written the words "equality", "freedom", "solidarity" and "happiness" in the margin: that reminded me of the slogans of the French Revolution, of course, and I began to see that turning concepts inside out was their way of conduct-

\footnotetext{
${ }^{2}$ Translation by Henrik Juel.
} 
ing critique: what has happened to the good old slogans, the dreams and ideals of the Enlightenment? I began to see critique of ideology as not just (as some textbooks will have it by means of a quick reading of Karl Marx) a flat rejection of "necessary, false consciousness" but also as an attempt, however desperate, to rescue and preserve the positive content of the ideologies. It is pleading for a fulfilment of the promises. And this is of course a well-known and powerful rhetorical tool, as when Martin Luther King in his last speech, given the night before he was killed, said: "All we say to America is, "Be true to what you said on paper"'"'3 (King 1968).

So Horkheimer and Adorno scorned the culture industry of their day for parading as having fulfilled the old promises of freedom, solidarity, happiness, and individuality (as something more than just white teeth and no arm sweat). To them, the culture industry seemed to have as its goal the elimination of all critical thinking about this state of affairs:

"The freedom that is promised by entertainment is that from thinking and from negating (refusing). The infamy of the rhetorical question: "What do people want!" lies in the fact, that it is referring to as thinking subjects the same people, whose subjectivity it aims at eliminating" (Horkheimer and Adorno 1969, 130).

The question still remains: how would Horkheimer and Adorno evaluate modern social media? Is truly critical thinking perhaps after all possible within social media - remembering that social media have now taken on a rather different form, allowing replies and user-generated content? Social media actually seem to be a success due to their allowing people to indulge in all sorts of subjectivity and protests.

In order to illuminate this question a little more it would be worthwhile to return to the first section of the book, called "The Concept of Enlightenment", where Horkheimer and Adorno are outlining the grand history of civilization and rationality. This is a rather abstract account of the development of mankind's ways of dealing with nature, stretching from prehistoric magic to modern science and technology. A somewhat similar account of the development of rationality can be found in Adorno's later book on Aesthetic Theory, where it appears in the back of the book (Adorno 1970, $480,522)$.

This grand history proceeds through four phases, all fortuitously beginning with $\mathrm{M}$; at least that is how I find it convenient to label them: magic, mythology, metaphysics, and mathematics.

In prehistoric time we are to imagine that man was facing a really scary world; nature too huge, wild and complex for him to control or understand. Nature was the great wilderness - but slowly man began to grasp this great force, influence its impact on the human race and make earth into a safer home.

Through rites, rituals, offerings and diverse forms of mimetic behaviour (precursors of what we now know as artwork) man tried to come to terms with nature and the forces that shaped human destiny. Priests appeared, claiming to be able to perform magic and control nature, freeing society from nature's domination and perhaps also that of rival tribes. By this means they also gained status and power over their fellow men.

Man's growing capacity for dealing with nature, and his development of tools, weapons and other types of technology, went hand in hand with the development of society and the (self-) domination of man. The immediate forces of nature were transformed into mythological figures; gods still required to be honoured and they still reigned, but, by now, only in the background.

In the age of metaphysics the gods lose their resemblance to humans and are replaced by more abstract forces and principles - different areas of being are explained in a fairly systematic fashion, and the sciences appear. Science, which is all about understanding, explaining, predicting and producing the means to gain power over nature, also offers the power to control others who might be getting in our way (e.g. understanding how to navigate and how to bomb).

Finally mathematics and exact calculation win the race for ruling territory - it becomes the most successful form of rationality: it makes science and technology possible; it reshapes the way we live within nature and with each other. The exchange of commodities by means of an abstract equivalent (money) and capitalism's control of the means of production further advances this capacity for strategic thinking and the quantification of everything and everyone. Only what can be counted and measured counts, calculation and strategic behaviour become equal to being rational. Other ways of viewing and relating become obsolete forms and sink back into what is considered to be irrationality - seen in the same light as myths, magic and religion. Values, goals and morals come to be seen as subjective, as something outside the reach of reason. Some of these "older" variations, or pre-forms, of rationality are still considered nice and permissible within restricted ar-

\footnotetext{
${ }^{3}$ Martin Luther King held his last speech on April 3rd, 1968, in Memphis.

${ }^{4}$ Translation by Henrik Juel.
} 
eas, such as love and art, but reality is nevertheless only to be described and ruled by what parades as pure rationality: strategic and scientific and technological and economic development towards goals no longer (if ever) discussed.

The long history of enlightenment is thus the demystification of nature and the development of pure calculative rationality. What is left behind, however, such as the now obsolete frames of reference such as magic and myth, has a tendency to return. There is a dialectic backlash of the oppressed forms. The belief in science, in technology, in capitalism, in consumer goods, and in the stars of the media, takes on the air of worship, of ritual behaviour, fetishism and deliverance to blind fate. It has become difficult to think critically about alternatives to "the system" (e.g. "the financial system" is today above all a metaphysical term) and about its progress - as well as its possible crisis. We have developed the technological and productive capacities to do away with poverty, hunger and sufferings around the globe. That, however, is not what we see as impending. But we can still amuse ourselves by means of the culture industry that parades all promises of the enlightenment, the hopes of all scholars, scientists and artists, and all ideals of the bourgeois era as fulfilled - or just about to be so round the corner. And, at the least, if you win in the weekly lottery: then you will be truly happy.

So, according to Horkheimer and Adorno in their account of the history of enlightenment we have tried to free ourselves of the dangers and brute force of nature, but in the process of developing technology and production we have ended up narrowing our rational capacities, dominating ourselves and tying ourselves to a petrified system now even endangering our environment. Modern society has become the new scary jungle.

Now all of this seems to point towards a dead end for mankind, but why do we go there? What is it that keeps me - you, everybody, the masses - tied to following this sorry route? That has perhaps not yet been very well explained, but it seems to be a presupposition in the writings of Horkheimer and Adorno: What they are drawing on, and more or less taking for granted as common knowledge among their readers (who, like themselves, have somehow managed to keep up their level of critical thinking), are the mechanisms of alienation and fetishism as formulated by Marx. Now according to Marx the workers within the capitalist mode of production are not just poorly off because they are being exploited and paid less for their work than it is actually worth, they are also being alienated (i.e. becoming as a result estranged from themselves), because of the division of labour. They stand in the workshop or at the assembly line and put all of their effort and talents into the making of some detail of a product - which then disappears along the line and is seen no more by its maker. And that is a loss of self. Then a new item turns up and the workers once again invest their human capacities in this object, which then, once again, disappears.

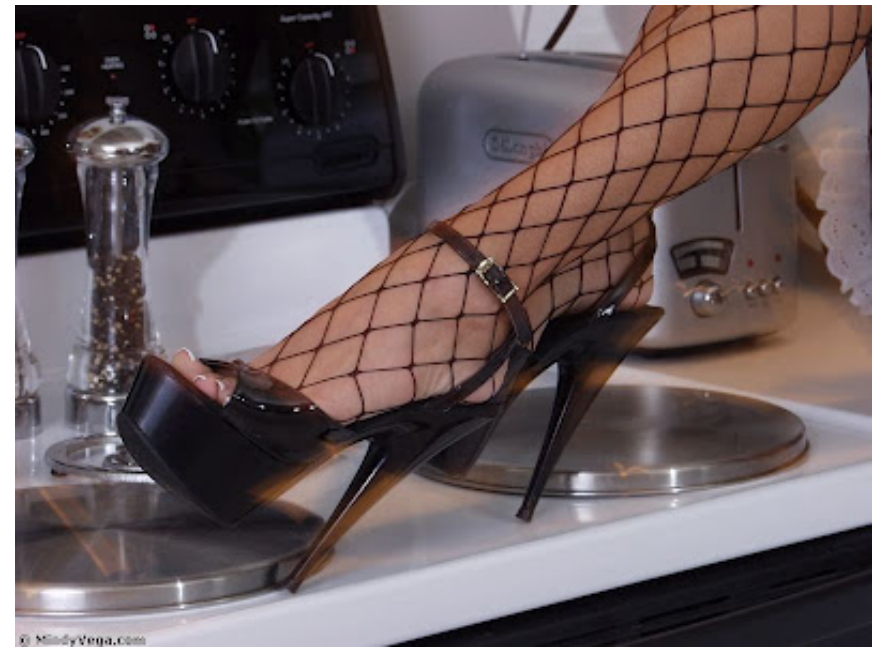

Figure 16: Kitchen utensils illustrating the Marxist concept of the fetishism of commodities?

After work hours the workers are turned into consumers and they automatically start looking for their lost powers and for ways to compensate for the lack of meaning in the routine work: they do that by worshipping the shiny commodities they see in the show windows. Actually they are just trying to make up for the loss of their own personal powers now hidden within the objects they do not own but have to buy. 
Searching the net for a good illustration of the Marxist concept of "Warenfetischismus" (the fetishism of consumer goods) comes up with some strange results, but I hope the illustration in figure 3 will 'do', and not distract the reader from critical thinking about theories of political economy.

One has of course to focus here on the nice kitchen utensils such as the toaster in the background. It is commodities like this we yearn to buy in order to make up for the alienation during our work hours. We have lost ourselves during work within capitalism, and the critical point Horkheimer and Adorno are so indignant about concerning the culture industry is that this whole show business is not offering any genuine compensation: we do not get our individuality or subjectivity or human powers back from watching advertisements showing us the young, the rich, and the beautiful.

But what about social media, do they have more to offer? They are after all not just one-way mass media like the old ones. Perhaps there is a lot of content of a very silly sort, and a lot of hidden or overt advertisement. Also the traditional institutions and centres of power use the Internet in order to maintain power and control. But the new social media do after all allow for some usergenerated content, they do allow for replies, for discussions - and so freedom of expression has become harder to suppress. And it seems to me that a lot of the traffic on social media is concerned with not just sending a message - that is perhaps the least of it - but it is all about people connecting with others in order to work out their individuality for themselves. There is a lot of identity work going on within social media. You can (in a variation of an old joke) even experiment with being a dog on the Internet if you like. So perhaps one can argue that social and personal life on the Internet now allows us somehow to overcome, or at least balance out, the alienation and solitude we supposedly experience at work - and maybe one can even argue that modern media and technology will change the fundamental mechanisms of work itself?

So having reconsidered some of the main points in Horkheimer and Adorno's Dialectic of Enlightenment I come back to my initial confusion about this topic. Now at least I can formulate it a little more precisely: Can social media really break the circuit of illusion, alienation and the backlash of the dialectic of enlightenment?

Or can we at least in part see social media as a sort of green house keeping alive (just like the function of authentic art according to Horkheimer and Adorno) whatever seeds and sprouts of hopes and dreams still remain - despite all the broken promises? Is critical thinking still possible and has modern social media even revitalized it?

Well, that is the question.

\title{
References
}

Adorno, Theodor W. 1970. Ästhetische Theorie. Frankfurt am Main: Suhrkamp.

Horkheimer, Max, and Theodor W. Adorno. 1969. Dialektik der Aufklärung. Frankfurt am Main: Suhrkamp.

King, Martin Luther. 1968. 'I've Been to the Mountaintop': Last speech held by Martin Luther King, Mason Temple, Mem-

phis, Tennessee. Accessed October 24, 2012. http://www.youtube.com/watch?v=MEDgdEt9sh8

\begin{abstract}
About the Author
Henrik Juel

Born 1951. Mag. art and cand. mag in Philosophy and Nordic Philology, Ph.D. in Communication Studies. Associate Professor at the Department of Communication, Business and Information Technologies (CBIT), Roskilde University, where he teaches video production and film theory, aesthetics, communication theory and rhetoric. Research in film phenomenology, rhetoric and didactics. Long standing interest in the aesthetics of nature and creative and philosophical video production. More information and articles in English can be accessed at: http://akira.ruc.dk/ hjuel/
\end{abstract}

